\title{
BMJ Open Quality How critical cost analysis can save money in today's NHS: a review of carpal tunnel surgery in a district general hospital
}

Mark Williamson, Ranjit Sehjal, Mark Jones, Chris James, Andrew Smith

To cite: Williamson M, Sehjal R, Jones M, et al. How critical cost analysis can save money in today's NHS: a review of carpal tunnel surgery in a district general hospital.BMJ Open Quality 2018;7:e00115. doi:10.1136/ bmjoq-2017-000115

Received 15 May 2017 Revised 22 March 2018 Accepted 8 April 2018
Check for updates

Department of Orthopaedics, East Kent Hospitals University NHS Foundation Trust, Canterbury, UK

Correspondence to Mark Williamson; mark.williamson@doctors. org.uk

\section{ABSTRACT}

With today's National Health Service (NHS) facing huge financial pressures the healthcare profession cannot afford to carry on spending at the current rate. Individual clinicians should be encouraged to critically appraise their own practices to bring about a more efficient and costeffective service.

The purpose of this project was to analyse the way that carpal tunnel surgery was being performed within our institution and bring about safe changes to practice that reduce expenditure.

By critiquing our practices and applying simple changes based around sound evidence an annual saving of over $£ 15500$ to the department was made. The changes instigated are simple, sustainable and safe to implement while providing improved patient satisfaction. They are also easily transferrable across institutions and to other minor hand surgical procedures to afford even greater ongoing savings to the NHS.

\section{PROBLEM}

At our institution, there are currently two orthopaedic hand surgeons who together will conduct in the region of 500 carpal tunnel decompression (CTD) procedures each year in the day surgery unit. The surgical technique used is a standard open approach for decompression of the median nerve. The practice prior to our analysis involved CTD to be performed under a local anaesthetic of $10-15 \mathrm{~mL}$ of $0.5 \%$ Chirocaine using a disposable tourniquet to aid in a blood-free surgical field. Standard operative time is approximately 7-10 min.

Given the prevalence of carpal tunnel syndrome (CTS) and the high number of CTD procedures conducted at our establishment we decided to analyse our practice to establish areas where costs could be minimised while still preserving quality of patient care and safety. Our study was conducted over a 6-month period and resulting changes have now become standard practice.

\section{BACKGROUND}

The National Health Service (NHS) net deficit for the 2015/2016 financial year was $£ 1.851$ billion according to NHS Confederation with a continued projected increase in total spending going forward. ${ }^{1}$ The NHS is struggling against an increasingly ageing population to manage financial balance and is operating consistently at a significant loss. As individual establishments, it is up to each hospital to look at how savings can be made across services while maintaining the quality and safety of care provided to their patients. As individual surgeons, it is also up to us to look at our own practice and establish areas where such improvements can be made.

CTS is the most common form of nerve entrapment in the upper limb, occurring when the median nerve is compressed at the level of the wrist within the carpal tunnel. In the UK, 88 men and 193 women present to their general practitioner as new cases per 100000 population. ${ }^{2}$ Of these patients, 43-74 per 100000 will go on to require a surgical decompression. ${ }^{3}$ There are currently around 53000 decompression procedures undertaken in secondary care each year. ${ }^{4}$ CTD is extremely effective in reducing CTS with success rates as high as $90 \%$ in randomised trials. ${ }^{56}$

\section{BASELINE MEASUREMENT}

By working with the procurement department, a detailed investigation of costings for the expendables used during a CTD was undertaken based on the standard surgical practice at our institution. The total costings of expendables worked out to be $£ 49.60$. The majority of this total cost consisted of instrument sterilisation costs for a full orthopaedic hand set (£23.58), a disposable tourniquet (£10.20) and a large hand drape (£6.67). A complete summary of costs is shown in table 1. 
Table 1 Cost comparison of initial versus revised expendables

\begin{tabular}{|c|c|c|c|}
\hline Initial expendables & Initial cost (£) & Revised expendables & Revised cost (£) \\
\hline $2 \times 10 \mathrm{~mL}$ syringe & 0.09 & $1 \times 20 \mathrm{~mL}$ syringe & 0.07 \\
\hline Needle & 0.11 & Needle & 0.11 \\
\hline $2 \times 10 \mathrm{~mL} 0.5 \%$ Chirocaine LA & 3.49 & $10 \mathrm{~mL}$ Xylocaine+epinephrine LA & 1.06 \\
\hline Tourniquet & 10.20 & Tourniquet not used & 0 \\
\hline Marker pen & 0.65 & Marker pen not used & 0 \\
\hline Full hand set (sterilisation) & 23.58 & Rationalised set (sterilisation) & 11.77 \\
\hline Large hand drape & 6.67 & Small aperture drape & 0.53 \\
\hline $2 \times$ size 15 blades & 0.15 & $2 \times$ size 15 blades & 0.15 \\
\hline $1 \times 4.0$ absorbable suture & 3.19 & $1 \times 4.0$ absorbable suture & 3.19 \\
\hline Dressing & 0.07 & Dressing & 0.07 \\
\hline Wool & 0.80 & Wool & 0.80 \\
\hline Crepe & 0.60 & Crepe & 0.60 \\
\hline Total & 49.60 & & 18.35 (31.25 saving) \\
\hline
\end{tabular}

\section{DESIGN}

To establish how cost savings could be achieved, a meeting between the two hand surgeons and all theatre personnel involved in performing CTD procedures at our institution was held. We systematically broke down the procedure into individual steps, critically analysing the consumables used. Once a complete list of consumables and costs had been established and attributed to each individual stage of the procedure, each step was appraised for potential improved alternatives based around a comprehensive review of the current literature to ensure that any changes proposed were evidence based and afforded a safe and effective alternative.

Wide-awake, local anaesthesia, no tourniquet (WALANT) hand surgery is a concept that has been showing increasing popularity among institutions worldwide. The use of a local anaesthetic with epinephrine for surgery involving the hand and wrist has been demonstrated by several studies to provide excellent haemostasis, negating the standard use of a tourniquet to provide a bloodless operative field with the added benefit of removing the associated tourniquet pain. ${ }^{7-9}$ Although the use of local anaesthetic with epinephrine has traditionally been discouraged in the hand due to perceived risk of digital ischaemia, review of the literature amounting to over 4000 patients receiving injections of epinephrine into the hand or fingers did not demonstrate any ischaemic complications, suggesting that such practice is safe. ${ }^{9}$ From the cost saving perspective, a recent study by Rhee et al examining the cost savings and patient experience of WALANT hand surgery in the clinic setting at a military medical centre in the USA demonstrates considerable cost savings as well as a high level of patient satisfaction. ${ }^{10}$ This study further backs up the findings by Leblanc et al in the Canadian healthcare system, which also demonstrated the cost savings and safety of WALANT surgery, again in the clinic setting. ${ }^{11}$ Currently, there is no similar analysis of WALANT surgery for carpal tunnel and other hand procedures in the UK.

How patients are draped for a surgical procedure can also result in substantial differences in cost. When considering minor hand surgical procedures there is evidence supporting the effectiveness of field sterility, where only the hand being operated on is prepped and draped, as opposed to full operating theatre sterility necessitating the whole patient to be covered. Leblanc et al prospectively examined a cohort of over 1500 patients who underwent carpal tunnel surgery in minor procedure rooms using field sterility with the surgeons only wearing gloves and a mask and not full theatre gowns. The results of their study demonstrate a $0.4 \%$ superficial infection rate with 0 deep infection. ${ }^{12}$ A systematic review by Jagodzinski $e t$ al analysed surgical site infection after hand surgery carried out in a clinic setting. This study demonstrated that minor hand surgery could be performed outside the operating theatre using field sterility, without increasing the risk of infection. ${ }^{13}$ It is important to consider that in the current set-up within our establishment, procedures are carried out within the operating theatre as opposed to a minor procedure room or clinic room setting such as in the studies described.

\section{STRATEGY}

Based on the costings established and the literature review several areas for change were highlighted that would offer significant and safe cost savings. First, changing the type of local anaesthetic used to Xylocaine with adrenalin instead of using $0.5 \%$ Chirocaine. The Xylocaine plus epinephrine local anaesthetic would still produce a good quality of anaesthesia but also deliver a haemostatic effect via localised vasoconstriction. This change in type of anaesthesia would also negate the need for a disposable tourniquet. Both these changes would convey a cost 
saving and the patient would benefit from not having the discomfort of the tourniquet pressure throughout the procedure.

The significant cost of the drapes being used was also highlighted by our analysis. The large orthopaedic hand drapes with elasticated aperture are suited to providing full operating theatre sterility, suitable for major hand and wrist procedures including arthroplasty surgery. These drapes were switched to a smaller aperture drape that still afforded an appropriate level of sterility and field cover.

The sterile instrument sets were also a significant area highlighted during our analysis. A standard orthopaedic hand set containing 32 instruments was being used for CTD. These instrument trays were undergoing autoclave sterilisation at a significant cost following each use with many the instruments remaining unused. By rationalising the instrumentation required for performing minor hand procedures such as CTD into a smaller set of 10 instruments this significantly reduced sterilisation costs.

Further smaller savings were made by ensuring the use of appropriately sized syringes for anaesthetic administration. Skin marking pens were also not routinely used for incision planning.

A final meeting between the two hand surgeons and the operating theatre personnel was held once analysis and research was completed with the above proposed changes being put forward and agreed. All changes were instigated universally across the department at the same time.

\section{RESULTS}

The changes to practice amount to a procedure cost reduction of $£ 31.25$, equating to a $63 \%$ saving from the original cost. Multiplying this saving over the course of a year, considering a total of around 500 CTD procedures performed by two surgeons, results in an estimated annual saving of $£ 15625$ to the department. Extrapolating our own cost savings to the rest of the UK could result in cost savings in excess of $£ 1.5$ million assuming our department's practice were average. The cost savings from the instigated changes to practice are summarised in table 1.

Our experience was that local anaesthetic with epinephrine provided a good quality bloodless field affording a safe and effective surgical decompression of the median nerve without the need for a tourniquet. There was no discernible difference to the time taken to perform CTD with the revised equipment and anaesthetic technique.

\section{LESSONS AND LIMITATIONS}

The primary limitation of this project is that it focuses solely on the cost minimisation of expendables used during CTD procedures. It is beyond the power of this study to establish the potential cost savings that could be afforded when such procedures are performed out of the operating theatre environment in clinic rooms, as is more common in the USA and Canada. This study also does not consider surgeon and operating theatre personnel costs, which is clearly a significant factor in costings. However, in our study, there was no change to the number of theatre personnel required to perform CTD procedures with the revised equipment.

When implementing the changes to practice there were a number of issues that arose. Due to the design of the study we instigated all of the proposed changes at the same time. We did find that this approach made things difficult for clinical staff initially. This was due largely to the fact that the clinical team had been performing CTD procedures in exactly the same way for a long period. The resulting errors involved wrong drapes and tourniquets being accidently opened and thus initially negating any savings to cost. In retrospect we would recommend that changes be instigated one at a time over a staggered time frame to allow clinical staff to adopt a single change before then moving on to introducing further changes to practice. By adopting this more organised approach these initial errors could then be minimised. We also initially found that we ran out rationalised instrument sets when we had more CTD procedures booked onto lists than we had sets. Although this problem was relatively easily solved once identified this could have been avoided altogether if clerical staff involved in booking patients onto lists had been informed regarding the maximum number of CTD procedures that could take place on a single theatre list during the transition period to new practice. More rationalised sets were rapidly put together and made available which resolved this issue.

The other limitations noted include the need for ongoing long-term follow-up to ensure infection rates postsurgery remain unchanged. Given the evidence available it was felt that the changes made were safe to instigate. Further research is planned in the form of patient satisfaction studies to insure there has been an appreciable improvement following the switch to using no tourniquet.

\section{CONCLUSION}

The changes brought about by our institution have demonstrated that taking a critical systematic approach to reviewing current practice, backed up by solid evidence in the literature, can bring about safe and significant improvements in departmental expenditure that are sustainable.

Although the changes in this review have focused specifically on CTD surgery they can easily be applied to trigger finger release and other superficial soft tissue hand procedures, affording further significant savings.

As previously alluded to, the NHS is under significant financial pressure. In the current climate, individual clinicians must be responsible for critically appraising the way that they deliver a service and actively seek out the areas of inefficiency and excess expenditure. It is all too easy to become set in a way of delivering a service but this is something that must be actively challenged. 
The changes described in this review can be easily adapted and applied across other NHS institutions and specialties, including primary care. By clinicians and the teams that they work within adopting an active approach to cost saving, even the smallest and simplest of changes can make big differences to cost and efficiency. In an economic environment where the NHS deficit is growing at the rate it is we must ask ourselves can we afford not to change the way care is delivered?

Contributors MW: original idea, design and instigation of quality improvement changes, research and writing of paper. RS and MJ: assisting with instigation of quality improvement changes, assisting with research and writing of paper. CJ and AS: senior authors, assisting with instigation of changes, review and editing of paper prior to submission.

Funding The authors have not declared a specific grant for this research from any funding agency in the public, commercial or not-for-profit sectors.

Competing interests None declared.

Patient consent Not required.

Provenance and peer review Not commissioned; externally peer reviewed.

Open Access This is an Open Access article distributed in accordance with the Creative Commons Attribution Non Commercial (CC BY-NC 4.0) license, which permits others to distribute, remix, adapt, build upon this work non-commercially, and license their derivative works on different terms, provided the original work is properly cited and the use is non-commercial. See: http://creativecommons.org/ licenses/by-nc/4.0/

(c) Published by the BMJ Publishing Group Limited. For permission to use (where not already granted under a licence) please go to http://www.bmj.com/company/ products-services/rights-and-licensing/

\section{REFERENCES}

1. NHS Confederation, Key Statistics on the NHS. www.nhsconfed.org/ resources/key-statistics-on-the-nhs (accessed 26 Feb 2017).

2. Latinovic R. Incidence of common compressive neuropathies in primary care. Journal of Neurology, Neurosurgery \& Psychiatry 2006;77:263-5.

3. Aroori S, Spence RAJ. Carpal tunnel syndrome. Ulster Medical Journal 2008;77-1:6-17.

4. Hospital Episode Statistics 2011/12. Leeds: Information Centre NHS, 2012.

5. Gerritsen AA, de Vet HC, Scholten RJ, et al. Splinting vs surgery in the treatment of carpal tunnel syndrome: a randomized controlled trial. JAMA 2002;288:1245-51.

6. Huisstede BM, Randsdorp MS, Coert JH, et al. Carpal tunnel syndrome. Part II: effectiveness of surgical treatment-a systematic review. Arch Phys Med Rehabil 2010;91:1005-24.

7. McKee DE, Lalonde DH, Thoma A, et al. Optimal time delay between epinephrine injection and incision to minimize bleeding. Plast Reconstr Surg 2013;131:811-4.

8. Lalonde D, Martin A. Epinephrine in local anesthesia in finger and hand surgery: the case for wide-awake anesthesia. J Am Acad Orthop Surg 2013;21:443-7.

9. Thomson CJ, Lalonde DH, Denkler KA, et al. A critical look at the evidence for and against elective epinephrine use in the finger. Plast Reconstr Surg 2007;119:260-6.

10. Rhee PC, Fischer MM, Rhee LS, et al. Cost savings and patient experiences of a clinic-based, wide-awake hand surgery program at a military medical center: a critical analysis of the first 100 procedures. J Hand Surg Am 2017;42:e139-e147.

11. Leblanc MR, Lalonde J, Lalonde DH. A detailed cost and efficiency analysis of performing carpal tunnel surgery in the main operating room versus the ambulatory setting in Canada. Hand 2007;2:173-8.

12. Leblanc MR, Lalonde DH, Thoma A, et al. Is main operating room sterility really necessary in carpal tunnel surgery? A multicenter prospective study of minor procedure room field sterility surgery. Hand 2011;6:60-3.

13. Jagodzinski NA, Ibish S, Furniss D. Surgical site infection after hand surgery outside the operating theatre: a systematic review. J Hand Surg Eur Vol 2017;42:289-94. 